\title{
Desvendando o conteúdo da capacidade civil a partir do Estatuto da Pessoa com Deficiência
}

\section{Unraveling the content of legal capacity from the Statute Person with Disabilities}

\author{
Joyceane Bezerra de Menezes* \\ Ana Carolina Brochado Teixeira*
}

\section{Resumo}

A lei no.13.146/2016 tem seu fundamento na Convenção Internacional das Pessoas com Deficiência e trouxe modificações importantes quanto à abordagem da deficiência. Norteia-se pelo modelo do apoio em detrimento ao paradigma de substituição da vontade. Para o Direito Civil, a mudança estrutural se refere à capacidade. O Código Civil restringia a capacidade civil de acordo com uma ideia quantitativa e estanque atrelada a modelos "pret a porter" que presumiam falta do discernimento. A divisão entre incapacidade absoluta e relativa não atinge mais as pessoas com deficiência, na medida em o Estatuto previu apenas algumas situações que se encaixam na categoria de incapacidade relativa. Para os demais casos, a capacidade estará sempre preservada. Se houver necessidade de algum apoio, esse será autorizado mediante processo judicial que analise a situação pessoal da pessoa com deficiência. É dever do intérprete reconstruir as categorias dogmáticas para que possa proteger melhor e garantir a inclusão social à pessoa com deficiência.

Palavras-chave: Capacidade civil. Código Civil. Pessoa com deficiência.

Doutora em Direito pela Universidade Federal de Pernambuco. Mestre em Direito pela Universidade Federal do Ceará. Professora titular da Universidade de Fortaleza. Programa de Pós-Graduação Strictu Senso em Direito (Mestrado/Doutorado) da Universidade de Fortaleza, na Disciplina de Direitos de Personalidade. Professora adjunta da Universidade Federal do Ceará. Editora da Pensar - Revista de Ciência Jurídica da Universidade de Fortaleza. Fortaleza - Ceará - Brasil. E-mail: joyceane@unifor.br

* Doutora em Direito Civil pela UERJ. Mestre em Direito Privado pela PUC Minas. Especialista em Direito Civil pela Scuola di Diritto Civile da Università di Camerino. Professora de Direito Civil do Centro Universitário UNA e advogada. Belo Horizonte - Minas Gerais - Brasil. E-mail: anacarolina.bt@uol.com.br 


\section{Abstract}

The law no.13.146 / 2016 is based on the International Convention on Persons with Disabilities and brought important changes regarding the approach to disability. It is based on the person support model and not the paradigm of substitution will. The Civil Code restricted legal capacity according to a quantitative and watertight idea linked to models " pret a porter " that presumed lack of discernment. The division between absolute and relative inability does not reach more people with disabilities, as the Statute predicted just a few situations that fit into the category of relative inability. For the other cases, the capacity will always be respected. If you need some support, that will be authorized by judicial process to examine the personal situation of the disabled person. It is the duty of the interpreter rebuild the dogmatic categories so you can better protect and ensure social inclusion for people with disability .

Keywords: Legal capacity. Civil Code. Persons with disabilities.

\section{Introdução}

O advento do Estatuto da Pessoa com Deficiência, em janeiro de 2016, trouxe muitas dúvidas a respeito da interpretação e operacionalização de seu conteúdo: é possível quealguém curatelado seja capaz? As pessoas sujeitas à curatela serão relativamente incapazes? Como a pessoa sem nenhum discernimento tomará pessoalmente as decisões a respeito de suas situações existenciais? Se alguém não tem discernimento e necessita da curatela, esta, necessariamente, limitada ao campo negocial ou será possível modular os poderes do curador à situação fática da pessoa em todas as hipóteses? Como ficarão a teoria das invalidades e a prescrição se a pessoa com deficiência não é mais incapaz?

Não pretendemos, nesse estudo, tentar responder todas essas perguntas, mas refletir e delinear o atual conteúdo do instituto da Capacidade, a partir da historicidade do seu conceito, passando pelos paradigmas inaugurados pela Convenção Internacional das Pessoas 
com Deficiência (CDPD) e o Estatuto das Pessoas com Deficiência (EPD).

\section{Revisitando conceitos clássicos: personalidade, capacidade de direito e capacidade de exercício}

Tendo em vista o novo paradigma inaugurado pelo Estatuto da Pessoa com Deficiência, faz-se necessário passar em revista brevemente os clássicos conceitos de personalidade, capacidade de direito e capacidade de exercício. Personalidade exprime a possibilidade de alguém participar de relações jurídicas, decorrente de qualidade inerente ao ser humano que lhe confere a titularidade de direitos e deveres (AMARAL, 2006, p.216), constituindo-se seu viés subjetivo. Sob a perspectiva objetiva, a personalidade é tomada como objeto de proteção do ordenamento jurídico, como um conjunto de atributos inerentes ao ser humano, que garantem a sua integridade e a sua dignidade. (TEPEDINO, 2004, p.26). Assume então, a posição jurídica central do nosso ordenamento e torna-se objeto de proteção através dos direitos de personalidade - o que é inerente, apenas, à pessoa natural.

Nos moldes atuais - após a Convenção e o Estatuto - é necessário rever os termos até então utilizados pela doutrina para tratar do tema da capacidade. Esta, enquanto gênero abrange duas espécies: a capacidade de direito e a de fato. A grande confusão que vem sendo feita após o advento do EPD - ao interpretá-lo segundo a Convenção -, se refere ao termo capacidade legal ou jurídica (utilizada pela CDPD e pelo EPD como capacidade enquanto gênero), na medida em que essa expressão vinha sendo utilizada pela doutrina como sinônimo de capacidade de direito ${ }^{1}$. Por isso, a necessidade de se fazer uma

\footnotetext{
"A matéria versada no parágrafo em exame e nos anteriores parágrafos 47 e 48 conserva a atualidade, fundamentalmente na distinção de base entre capacidade de obrar (ou capacidade de exercício) e capacidade de direito (capacidade jurídica)[...]" (Atualizadores de Pontes de Miranda em PONTES DE MIRANDA, 2012, p. 250).
} 
revisitação crítica de tais termos à luz dos instrumentos legislativos contemporâneos, a fim de se redimensionar o novo conteúdo dos antigos institutos jurídicos ${ }^{2}$. Note-se que Caio Mário da Silva Pereira (1997, p.161), que já utilizava o termo capacidade jurídica quando se referia ao gênero capacidade: "Personalidade e capacidade completamse: de nada valeria a personalidade sem a capacidade jurídica que se ajusta assim ao conteúdo da personalidade, na mesma e certa medida em que a utilização do direito integra a ideia de ser alguém titular dele".

A capacidade de direito (capacidade civil, de gozo) é a projeção do valor personalidade no mundo jurídico, bem como um atributo da personalidade. Esta é reconhecida pelo ordenamento; já a personalidade é concedida por ele. Capacidade é manifestação dos poderes de ação inerentes à personalidade, constituindo-se em medida jurídica desta.

Todas as pessoas, físicas e jurídicas, têm capacidade de direito, por força do que estabelece o artigo $1^{\circ}$ do Código Civil. Enquanto a capacidade de direito é a aptidão para alguém ser titular de direitos e deveres, em seu sentido subjetivo, a capacidade de exercício (ou de fato, de agir, geral, plena) é a aptidão para a "prática dos atos da vida civil, e para o exercício dos direitos como efeito imediato da autonomia que as pessoas têm". (AMARAL, 2006, p.227). Ela remete ao discernimento, à higidez psíquica, à capacidade mental de mensurar a consequência dos atos realizados. Para Ebert Chamoun (1977, p.48), capacidade de fato refere-se a uma noção concreta e positiva de titularidade mediata e, à medida que se realiza, através da manifestação de uma vontade, exigese que a vontade esteja formada e que a pessoa haja adquirido certa maturidade. Daí, conclui-se que a capacidade de exercício é instrumento de realização da autonomia privada, por estar estreitamente ligada à

O direito argentino tem a mesma concepção: "La capacidad jurídica (o, simplesmente, capacidad) es el atributo de la personalidad que permite que toda persona sea apta para ser titular de derechos y obligaciones; de ejercitar los primeiros y contraer los segundos en forma especial. [...] En el Codigo de Vélez Sarsfield (mantenida em el actual) la capacidad es la regla general [...]; se regulan dos tipos de capacidades, la de derecho y la de hecho." (SUBIES, 2015, p. 13). 
prática de atos jurídicos, que criam, modificam ou extinguem relações jurídicas ${ }^{3}$.

Todos têm capacidade de direito, embora nem todos tenham a plena capacidade de fato. Para a configuração da primeira, basta o nascimento com vida, para as pessoas físicas, ou o registro dos atos, bem como o atendimento aos requisitos legais de constituição, para a pessoa jurídica. Já o pressuposto de fato da capacidade de agir é a capacidade de querer e de entender. ${ }^{4} \mathrm{~A}$ vontade e o entendimento são os guias da ação, cuja manifestação a lei considera necessária para que os atos humanos produzam efeitos civis ${ }^{5}$. Por conseguinte, a incapacidade de agir induz à incapacidade de querer e de entender, que se traduz na impossibilidade não de assumir comportamentos jurídicos, mas de assumi-los validamente. (ARENA, 1958, p.915-916).

Tendo em vista a falta de pressupostos materiais para que algumas categorias de pessoas se conduzam com autonomia, em face da ausência de experiência e maturidade no trânsito jurídico, estabeleciase o regime das incapacidades para os menores e para aqueles cuja

3 Judith Martins Costa refere-se à capacidade para consentir como uma espécie distinta que escaparia à construção dogmática da capacidade jurídica (MARTINS-COSTA, 2009, p.299-346). Todavia, entendemos que a capacidade de consentir em matéria de bioética é um reflexo da própria capacidade de agir - ou seja, a capacidade geral de querer e entender um determinado resultado. Essa mesma capacidade é que balizará a capacidade jurídica do sujeito para a prática dos atos negociais.

4 "La capacità di intendere, che è posta alla base della capacità legale e naturale di agire, è expressione della idoneità del soggetto a prendere cognizione non solo dei risultati di un'azione [da lui] voluta, ma anche delle situazioni della realtà che precedono l'assunzione di un qualsiasi comportamento, al fine di avere presenti $i$ dati allá luce dei quali andrà valutato il risultato dell'azione. La capacità di agire presuppone, in talune circostanze, l'esistenza e la conoscenza dei fatti che rendono l'azione del soggetto possibile o necessária" (ARENA, 1958, p. 920). Tradução livre: A capacidade de entender, posta na base da capacidade legal e natural de agir, é expressão da idoneidade do sujeito, de ter consciência não apenas dos resultados de uma ação [da sua] vontade, mas também das situações da realidade que precedem a assunção de qualquer comportamento, com o objetivo de ter presentes os dados, à luz dos quais será valorizado o resultado da ação. A capacidade de agir pressupõe, em alguma circunstância, a existência e o conhecimento dos fatos que levam à ação possível ou necessária do sujeito.

5 "La calidad jurídica más importante del hombre es la capacidad de obrar, es decir, la condición de la voluntad que la ley considera necesaria para que de los actos humanos deriven efectos jurídicos." (TUHR, 1999, p. 379-380). 
doença impedia o discernimento, total ou parcialmente. Conforme se verá, o Estatuto da Pessoa com Deficiência, em razão das diretrizes inovadoras da Convenção da Pessoa com Deficiência, modificou essa estrutura da incapacidade para retirar os deficientes em geral desse rol, na medida em que o paradigma é da inclusão e que uma concepção moderna entende que tais deficiências não se traduzem em doença ou enfermidade, mas em uma diversidade funcional ${ }^{6}$.

Embora o ordenamento jurídico Ihes atribuísse capacidade de direito, negava-Ihes a autodeterminação, impedindo-Ihes o exercício dos direitos, pessoal e diretamente. Exigia, para isso, a intervenção de outrem, seu representante ou assistente, dependendo de a incapacidade ser absoluta ou relativa, respectivamente. (PEREIRA, 2004, p.264). Mesmo assim, entendia-se que a regra geral é a capacidade, enquanto a incapacidade, a exceção. Por isso, e por se tratar de uma restrição à autonomia privada, ela não se presume; deve ser expressamente decorrente de lei ou de sentença judicial em processo de interdição.

\subsection{Incapacidade absoluta e incapacidade relativa até $o$ advento do EPD}

Em razão de a capacidade de fato atribuir aptidão a alguém para a produção de efeitos jurídicos a partir de sua atuação (ANDRADE, 1997, p.31), é sabido que não são todos os sujeitos que têm condições reais de exercê-la, o que nos leva a estudar as hipóteses de restrição da capacidade de fato, ou o regime das incapacidades. Este se referia

6 "Además de la intervención en el campo del Derecho y la bioética, la consecución de la plena dignidad de las mujeres y hombres con diversidad funcional, debe abordar un cambio terminológico, propuesto en este texto como parte del modelo de la diversidad. Este cambio terminológico tiene como objetivo la eliminación de la visión negativa de la diversidad funcional y la promoción de la visión de la diversidad funcional como parte de la diversidad humana, y por lo tanto como fuente de riqueza para la humanidad. En este cambio de visión social, imprescindible para la consecución de la plena dignidad en la diversidad funcional, resulta necesario también la completa desmedicalización de la diversidad funcional, eliminando la confusión entre enfermedad y diversidad funcional y reforzando la transversalidad, la idea de que la discriminación es común a todas las vertientes de la diversidad funcional, discriminación que adopta diferentes formas pero tiene un origen común, la merma de la dignidad." (PALACIOS; ROMAÑACH, 2016, p. 208). 
àquelas pessoas que, em virtude de sua falta de discernimento, não poderiam agir isoladamente no mundo jurídico, haja vista à ausência de condições intelectuais para o trânsito no mundo jurídico de forma consciente e responsável.

Sob a ótica do CC/02, a capacidade de fato da pessoa natural pode ser restringida, total ou parcialmente, por variadas circunstâncias atreladas à ausência ou comprometimento de discernimento. A incapacidade de agir é mensurada em graus, razão pela qual a presença de tais fatores pode gerar uma incapacidade total ou absoluta - que impede totalmente a prática de atos da vida civil -, ou a incapacidade parcial ou relativa - que demanda a assistência de um terceiro para acompanhar o relativamente incapaz na prática da maioria dos atos jurídicos.

Diante de tais situações, foi necessário encontrar soluções que contornassem a incapacidade, tendo em vista a necessidade de qualquer pessoa, independente de ser ou não capaz, participar da vida em sociedade. Por isso, o Direito estabeleceu formas de suprimento da incapacidade. Quando absoluta, a incapacidade deverá ser suprida através da representação do incapaz, instituto que determina que a vontade do representante substitua a vontade do incapaz; caso o incapaz pratique algum ato sozinho, a hipótese é de nulidade, conforme o artigo 166 do CCB/02, de modo que o ato não possa ser convalidado por seu representante.

Já na sua forma parcial, pelo fato de a incapacidade ter sido relativizada, o incapaz deve praticar atos conjuntamente com seu assistente, não obstante já possa realizar sozinho certos atos (ser testemunha, fazer testamento etc.). Caso pratique sozinho ato que deveria ser acompanhado de seu assistente, configura-se hipótese de anulabilidade, conforme o artigo 171 do CCB/02. Não obstante esta possibilidade, o ato pode ser ratificado por seu assistente.

O CCB/02 estabelecia, em seu artigo $3^{\circ}$, que eram absolutamente incapazes os menores de 16 anos, aqueles que por enfermidade ou deficiência mental não tiverem o necessário discernimento para a 
prática dos atos da vida civil, bem como os que, mesmo em razão de causa transitória, não puderem exprimir sua vontade. O Direito afasta tais pessoas da atividade jurídica por considerá-las desprovidas do necessário discernimento, em razão de não terem ainda a idade necessária, de enfermidade mental ou de alguma causa transitória que Ihes impeça a livre manifestação de vontade. O Estatuto da Pessoa com Deficiência modificou o art. $3^{\circ}$ para que fossem considerados absolutamente incapazes exclusivamente os menores de 16 anos.

A incapacidade relativa se restringe a determinados atos, por se entender que a pessoa já tem alguma maturidade que lhe permite praticar, sozinha, alguns atos da vida civil, repita-se. Os relativamente incapazes para certos atos são os maiores de 16 e menores de 18 anos, os ébrios habituais, os viciados em tóxicos e os que, por doença mental, tenham o discernimento reduzido, os portadores de necessidades educacionais especiais na área da deficiência mental, sem desenvolvimento mental completo, além dos pródigos ${ }^{7}$. A atual redação do art. $4^{\circ}$ retirou do rol dos relativamente incapazes as pessoas de discernimento reduzido e os excepcionais sem desenvolvimento mental completo; acrescentou, no entanto, aqueles que por causa transitória ou permanente não puderem exprimir sua vontade. Como se vê, as alterações produzidas pelo EPD, a partir da orientação da CDPD, excluem a deficiência como critério redutor da capacidade. Eventual resgate desse critério para o fim de mitigar a responsabilidade seria, portanto, inconstitucional, haja vista a natureza normativa da CDPD no ordenamento brasileiro. ${ }^{8}$

De acordo com Francisco Amaral (1988, p. 230), prodigalidade "não é doença, mas defeito de vontade, como determinantes da variação da capacidade de fato. Pródigo é o indivíduo com tendência para dissipar o seu patrimônio".

8 No Brasil, a Convenção foi ratificada por meio do Decreto n.186/2008, com quorum qualificado de três quintos nas duas casas do parlamento federal, em dois turnos, conforme instrui o art. $5^{\circ}$. $\S 3^{\circ}$., da Constituição Federal, logrando com isso, obedecer a hierarquia de Emenda Constitucional. Por meio do Decreto Presidencial n. 6949/2009, o Presidente da República sancionou aquele decreto legislativo, visando ainda, garantir o rito normalmente aplicável à ratificação e promulgação dos tratados internacionais. 


\subsection{Função do regime das incapacidades}

A função do regime das incapacidades é a proteção daqueles que não têm condições de transitar na vida civil de forma autônoma ${ }^{9}$. Sua finalidade precípua, dado o momento da sua criação (época do liberalismo), foi o resguardo do incapaz no trânsito jurídico patrimonial, para sua proteção nos negócios praticados, oferecendo maior segurança às relações jurídicas, o que ocorreu também no Brasil.

A incapacidade de agir ou de fato está circunscrita ao elemento patrimonial, concepção esta que é fruto de uma tradição em que advertem os influxos de uma elaboração científica de séculos, que não aproxima a capacidade de agir dos direitos do homem, mas sim, da realização de negócios e para a tutela da relação contratual ${ }^{10}$. Numa antiga concepção, os atos de autonomia privada, para o qual era necessário ser capaz, eram tidos como expressão do direito de propriedade e do tráfego comercial (STANZIONE, 1988, p. 10). Todavia, hoje, a tutela da pessoa não pode se exaurir apenas na esfera patrimonial.

Os critérios objetivos estabelecidos pelo CCB/02 podem ser eficazes, se se pensar nos aspectos patrimoniais da vida da pessoa absoluta ou relativamente incapaz inserida no tráfego jurídico, caso ela necessite de apoio para praticá-los. A capacidade do agente,

9 "O instituto das incapacidades foi imaginado e construído sobre uma razão moralmente elevada, que é a proteção dos que são portadores de uma deficiência juridicamente apreciável. Esta é a idéia fundamental que o inspira, e acentuá-lo é de suma importância para a sua projeção na vida civil, seja no tocante à aplicação dos princípios legais definidores, seja na apreciação dos efeitos respectivos ou no aproveitamento e na ineficácia dos atos jurídicos praticados pelos incapazes. A lei não institui o regime das incapacidades com o propósito de prejudicar aquelas pessoas que delas padecem, mas, ao contrário, com o intuito de lhes oferecer proteção, atendendo a que uma falta de discernimento, de que sejam portadores, aconselha tratamento especial, por cujo intermédio o ordenamento jurídico procura restabelecer um equilíbrio psíquico, rompido em conseqüência das condições peculiares dos mentalmente deficitários." (PEREIRA, 2004, p. 272).

10 Segundo Pasquale Stanzione (1988, p. 10), "l'analisi della capacità d'agire è svolta costantemente in una prospettiva economicistica, sí che raramente lo studio di essa si distacca dal profilo patrimoniale per investire altri aspetti della persona, quasi a conferma delle origini storiche dell'istituto. Sul piano dottrinale, la riprova dela fontatezza di tale asserzione è rappresentata dall'esistenza di teoriche che, in sede di definizione, ricollegano la concessione della capacità d'agire al fatto che il soggeto possieda la maturità sufficiente a valutare la convenienza economica degli atti che compie". 
prevista no artigo 104, CCB/02, é elemento essencial do ato jurídico lato sensu. Subsumido à capacidade do agente, o que se avalia são as condições psíquicas da pessoa para emitir sua vontade validamente, para responsabilizar-se pela execução da sua emissão volitiva ${ }^{11}$. Nessa esteira, afirma-se que o regime das incapacidades configura-se um estatuto privilegiado, na medida em que as restrições à capacidade de agir ou de fato não existem para alhear os incapazes, mas para integrálos ao mundo negocial. (EBERLE, 2006, p.139).

Tal definição é relevante, principalmente, para a prática de atos jurídicos patrimoniais, nos quais se faz necessária a fixação de parâmetros objetivos a serem seguidos pelas partes, de modo a atribuir eficácia aos negócios jurídicos e garantir a pacificação social. É escopo deste estudo investigar se o regime das incapacidades, criado para a tutela das situações patrimoniais, também se aplica às situações existenciais, pois não se pode ignorar que "mesmo que um sujeito de direito passe sua vida toda sem praticar nenhum ato ou negócio jurídico, de cunho patrimonial ou não, ainda assim será titular de um círculo mínimo de direitos de personalidade". (CARBONERA, 2004, p. 151). Nessas condições, titularidade e exercício de situações existenciais não podem ser cindidas, sob pena de haver uma disfunção das mesmas, que emanam do projeto de vida pessoal de cada $u^{12}{ }^{12}$. Pretende-se verificar tal posicionamento, através da leitura do regime das incapacidades

11 "Para o Direito, a vontade reveste-se de especial importância pela circunstância de constituir-se em um dos principais elementos do ato jurídico. Manifestando-se de acordo com os preceitos legais, a vontade produz determinados efeitos, criando, modificando ou extinguindo relações jurídicas, caracterizando, assim, a vontade jurídica" (AMARAL NETO, 1988, v. 46).

12 Há diversos autores que sustentam a incindibilidade entre titularidade do direito e capacidade para o seu exercício. Dentre eles, Pietro Perlingieri (La personalità umana nell'ordinamento giuridico, 1972); Pascoale Stanzione (Persona física. Diritto Civile, 1997); LISELLA, Gaspare. (Interdizione per infermità mentale e situazioni giuridiche esistenziali, 1982); RODRIGUES, Rafael Garcia (A pessoa e o ser humano no novo Código Civil, 2003); TEIXEIRA, Ana Carolina Brochado (Integridade psíquica e capacidade de exercício, 2008); MEIRELES, Rose Melo Vencelau (Autonomia privada e dignidade humana, 2009); MENEZES, Joyceane B (A capacidade dos incapazes: o diálogo entre a Convenção da ONU sobre os direitos da pessoa com deficiência e o Código Civil Brasileiro, 2014, p.51-74; e, LÔBO, Paulo. Direito Civil. Parte geral, 2010; SÁ, Maria de Fátima Freire; MOUREIRA, Diogo Luna. A Capacidade dos Incapazes: saúde mental e uma releitura da teoria das incapacidades no direito privado, 2011. 
à luz da legalidade civil-constitucional, tendo como pressuposto de investigação a possibilidade de se analisar a capacidade de agir sob um perfil funcional, com o escopo de verificar se ela deve ser aplicada de forma diferente de acordo com a natureza do ato, ou seja, declarações negociais ou não negociais de vontade.

Essa necessidade se faz imperativa, uma vez que a negação da capacidade no âmbito patrimonial trouxe consigo uma substancial negação em outros momentos da atividade humana, como as condutas de natureza pessoal, bem como aquelas atreladas à vida quotidiana. Ocorria, assim, uma expropriação da subjetividade e uma negação da autonomia própria, inerente à existência de cada um. Condenavase à marginalidade todas as decisões de conteúdo não patrimonial, construindo-se um paradigma fechado de "normalidade jurídica" (RODOTÀ, 2006, p. 26-27).

Foram muitos os debates doutrinários para que o regime das incapacidades fosse constitucionalizado. Pietro Perlingieri (2001) ressalta a superação de confusões entre inidoneidade para exercer atividades patrimoniais e enunciados proibitivos de escolhas existenciais significativas, tais como o casamento e o reconhecimento de filho:

É preciso privilegiar, sempre que for possível, as escolhas de vida que o deficiente psíquico é capaz, concretamente, de exprimir, ou em relação às quais manifesta notável propensão. A disciplina da interdição não pode ser traduzida em uma incapacidade legal absoluta, em uma 'morte civil'. Quando concretas, possíveis, mesmo se residuais, faculdades intelectivas e afetivas podem ser realizadas de maneira a contribuir para o desenvolvimento da personalidade, é necessário que sejam garantidos a titularidade e o exercício de todas aquelas expressões de vida que, encontrando fundamento no status personae e no status civitatis, sejam compatíveis com a efetiva situação psicofísica do sujeito. Contra essa argumentação não se pode alegar - sob pena de ilegitimidade do remédio protetivo ou do seu uso - a rigidez das proibições nas quais se consubstancia a disciplina do instituto da 
interdição, tendente à exclusiva proteção do sujeito: a excessiva proteção traduzir-se-ia em uma terrível tirania (PERLINGIERI, 2002, p. 164-165).

O que se constata, dessa forma, é que tal regime tem o intuito protetivo, mas não deve esgotar-se em si mesmo, pois só fará sentido se funcionalizado aos objetivos constitucionais. Se o suprimento da incapacidade visa o resguardo do trânsito jurídico patrimonial, tendo em vista que tenciona atribuir segurança às relações intersubjetivas, ele deve ser vista de forma qualitativamente diversa, no que tange às situações jurídicas existenciais.

Assim, não se pode mais ter como referência o conceito tradicional e estático de relação jurídica, no qual impera o sujeito de direito abstrato, e que ignora a incidência da pessoa humana concreta em dada situação jurídica, olvidando suas vicissitudes, que lhe permitem, algumas vezes, a tomada de certas decisões de máxima relevância para o próprio destino. Diante disso, a manutenção do regime das incapacidades para a prática de todas as categorias de atos jurídicos é um reforço à concepção patrimonialista do sistema jurídico. Já é corrente o entendimento da prevalência das situações jurídicas patrimoniais sobre as existenciais. ${ }^{13}$

Busca-se também que mesmo as situações jurídicas patrimoniais tenham sua justificativa institucional no fomento ao livre desenvolvimento da pessoa, razão pela qual a manutenção desses critérios para a prática de atos jurídicos existenciais se tornou insuficiente, como ressalta Pietro Perlingieri (2002, p.122)

13 "Diante, pois, da consolidação do marco teórico do direito civil-constitucional, com suas características essenciais já bastante difundidas, quais sejam: a prevalência das situações existenciais em relação às situações patrimoniais (ou a subordinação destas àquelas); [...]" (BODIN DE MORAES, 2008, p. 30); "Disto tudo decorre a necessidade de construção de uma nova dogmática do direito privado com coerência axiológica. Para tanto, na construção desta dogmática, há de se diferenciar, em primeiro lugar, as relações jurídicas patrimoniais das existenciais, já que fundadas em lógicas díspares. Tal diversidade valorativa deve preceder, como premissa metodológica, à atividade interpretativa. A pessoa humana é o centro do ordenamento, impondo-se assim tratamento diferenciado entre os interesses patrimoniais e os existenciais. Em outras palavras, as situações patrimoniais devem ser funcionalizadas à existenciais." (TEPEDINO, 2008, p. 365). 
Per gli interesse patrimoniali è ancora giustificato isolare il momento della titolarità del diritto (c.d. godimento) da quello della sua attuazione (c.d. esercizio); lo stesso non accade per gli interessi esistenziali. Se taluni diritti, piú di altri, sono concepiti ai fini dello sviluppo della persona umana (2 e 3 cost.), non ha senso riconoscere (astrattamente) uno di questi senza concedere anche la possibilita di esercitarlo ${ }^{14}$.

Perlingieri (2002, p.168) posiciona-se no sentido da necessidade de uma releitura constitucional dos limites impostos à capacidade, estabelecidos em forma rígida. Constata-se que, para situações existenciais, não há justificativa em separar-se a capacidade de direito da capacidade de fato, por ser intransferível o exercício dos direitos de personalidade.

Torna-se imperiosa, desta feita, a desconfiguração do sujeito de direito abstrato para, mais uma vez, valorar-se a pessoa humana concreta, inserida em determinada relação ou situação jurídica ${ }^{15}$. É nesta circunstância que se possibilita a efetiva realização da dignidade humana, levando-se em conta, inclusive, a possibilidade de autodeterminação ${ }^{16}$, de acordo com as condições próprias de cotejar liberdade e responsabilidade.

14 Tradução livre: Para os interesses patrimoniais é ainda justificado separar o momento da titularidade do direito (gozo) daquele da sua atuação (exercício); o mesmo não ocorre para os interesses existenciais. Se alguns direitos, mais que outros, são concebidos com a finalidade do desenvolvimento da pessoa humana (2 e 3 da Constituição), não há modo de reconhecer (abstratamente) um destes sem conceder, também, a possibilidade de exercitá-lo.

15 "A redução da ordem jurídica a verdadeiro estatuto patrimonial e a categorização da pessoa como sujeito que contrata, que constitui formalmente uma família, que tem um patrimônio e que se apresenta, enfim, como sujeito dos direitos estabelecidos no sistema, faz com que a personalidade civil se distancie mais e mais da dignidade humana, em razão da qual os indivíduos merecem proteção e amparo; e, aproxime-se, de maneira a sinonimizar-se, da titularidade contratual e patrimonial. Em suma, é a pessoa quem é titular; e só é titular quem a lei define como tal". (MEIRELLES, 2000, p. 98).

16 "[...] o reconhecimento de sua vulnerabilidade [da mulher, da criança, do adolescente, do idoso, do portador de necessidades especiais, do enfermo], impõe um tratamento normativo diferenciado, que busca empoderá-los na relação com os demais, de maneira a assegurar uma autonomia mais efetiva. Nesse sentido, são ditos novos sujeitos de direito, ou sujeitos merecedores de um tratamento jurídico diferenciado. (KONDER; TEIXEIRA, 2016, p.73). 
Feita a revisitação ao conteúdo da capacidade até então, buscase encontrar seu novo conteúdo, a partir dos novos paradigmas inaugurados pela Convenção e seguidos pelo Estatuto.

\section{A ideia contemporânea de capacidade a partir da Convenção sobre os Direitos das Pessoas com Deficiência e o Estatuto da Pessoa com Deficiência}

O escopo do EPD, cuja fundamentação imediata está na Convenção é a garantia de igualdade para a inclusão das pessoas com deficiência ${ }^{17}$. Para viabilizar essa inclusão, ambos os documentos

17 CDPD - "Preâmbulo Os Estados Partes da presente Convenção,

a) Relembrando os princípios consagrados na Carta das Nações Unidas, que reconhecem a dignidade e o valor inerentes e os direitos iguais e inalienáveis de todos os membros da família humana como o fundamento da liberdade, da justiça e da paz no mundo,

b) Reconhecendo que as Nações Unidas, na Declaração Universal dos Direitos Humanos e nos Pactos Internacionais sobre Direitos Humanos, proclamaram e concordaram que toda pessoa faz jus a todos os direitos e liberdades ali estabelecidos, sem distinção de qualquer espécie,

c) Reafirmando a universalidade, a indivisibilidade, a interdependência e a inter-relação de todos os direitos humanos e liberdades fundamentais, bem como a necessidade de garantir que todas as pessoas com deficiência os exerçam plenamente, sem discriminação, [...].

n) Reconhecendo a importância, para as pessoas com deficiência, de sua autonomia e independência individuais, inclusive da liberdade para fazer as próprias escolhas, [...].

Artigo 12 (Reconhecimento igual perante a lei): 1. Os Estados Partes reafirmam que as pessoas com deficiência têm o direito de ser reconhecidas em qualquer lugar como pessoas perante a lei. 2. Os Estados Partes reconhecerão que as pessoas com deficiência gozam de capacidade legal em igualdade de condições com as demais pessoas em todos os aspectos da vida. 3.Os Estados Partes tomarão medidas apropriadas para prover o acesso de pessoas com deficiência ao apoio que necessitarem no exercício de sua capacidade legal. 4.Os Estados Partes assegurarão que todas as medidas relativas ao exercício da capacidade legal incluam salvaguardas apropriadas e efetivas para prevenir abusos, em conformidade com o direito internacional dos direitos humanos. Essas salvaguardas assegurarão que as medidas relativas ao exercício da capacidade legal respeitem os direitos, a vontade e as preferências da pessoa, sejam isentas de conflito de interesses e de influência indevida, sejam proporcionais e apropriadas às circunstâncias da pessoa, se apliquem pelo período mais curto possível e sejam submetidas à revisão regular por uma autoridade ou órgão judiciário competente, independente e imparcial. As salvaguardas serão proporcionais ao grau em que tais medidas afetarem os direitos e interesses da pessoa. 5 . Os Estados Partes, sujeitos ao disposto neste Artigo, tomarão todas as medidas apropriadas e efetivas para assegurar às pessoas com deficiência o igual direito de possuir ou herdar bens, de controlar as próprias finanças e de ter igual acesso a empréstimos bancários, hipotecas e outras formas de crédito financeiro, e assegurarão que as pessoas com deficiência não sejam arbitrariamente destituídas de seus bens". 
reafirmam o princípio da dignidade da pessoa humana em duas de suas importantes perspectivas: a dignidade como dever que impõe ao Estado, à Sociedade e à Família prestações especificas voltadas para a proteção e a emancipação das pessoas com deficiência; e a dignidade como autodeterminação que sustenta a personalidade do sujeito com limitações intelectuais ou psíquicas, justificando a sua capacidade jurídica em igualdade com as demais. ${ }^{18}$

Para assegurar a dignidade como autodeterminação, a principal mudança introduzida pela CPDP (art. 12) ${ }^{19}$ e pelo EPD (art. $\left.6^{\circ}\right)^{20}$, no sentido de reconhecer a capacidade civil das pessoas com deficiência, revogando parcialmente o regime das incapacidades inscrito nos artigos $3^{\circ}$ e $4^{\circ}$ do Código Civil. ${ }^{21}$ Essa alteração tem sido objeto de calorosas discussões entre os juristas porque impacta no campo dos negócios jurídicos, da prescrição, da teoria das invalidades, da responsabilidade civil, das relações familiares etc., podendo, no plano da dogmática formal, causar desproteção e prejuízo aos interesses delas próprias.

Porém, autores importantes na área de filosofia do direito e dos direitos humanos, a exemplo de Gregório Peces-Barba, Stèfano

18 Agustina Palacius e Ravier Romañach (2016, p. 207-209) optam pelas expressões dignidade dignidade extrínseca e dignidade intrínseca, respectivamente.

19 "Art.12 - 2. Os Estados Partes reconhecerão que as pessoas com deficiência gozam de capacidade legal em igualdade de condições com as demais pessoas em todos os aspectos da vida".

20 "Art. 6o A deficiência não afeta a plena capacidade civil da pessoa, inclusive para:

I - casar-se e constituir união estável;

II - exercer direitos sexuais e reprodutivos;

III - exercer o direito de decidir sobre o número de filhos e de ter acesso a informações adequadas sobre reprodução e planejamento familiar;

IV - conservar sua fertilidade, sendo vedada a esterilização compulsória;

$\mathrm{V}$ - exercer o direito à família e à convivência familiar e comunitária; e

$\mathrm{VI}$ - exercer o direito à guarda, à tutela, à curatela e à adoção, como adotante ou adotando, em igualdade de oportunidades com as demais pessoas.

21 "Art. 3o São absolutamente incapazes de exercer pessoalmente os atos da vida civil os menores de 16 (dezesseis) anos.

Art. 4 ão incapazes, relativamente a certos atos ou à maneira de os exercer:

I - os maiores de dezesseis e menores de dezoito anos;

II - os ébrios habituais e os viciados em tóxico;

III - aqueles que, por causa transitória ou permanente, não puderem exprimir sua vontade;

IV - os pródigos.

Parágrafo único. A capacidade dos indígenas será regulada por legislação especial." 
Rodotà e Luigi Ferrajoli já firmaram posição no sentido de associar o princípio da dignidade da pessoa humana à ideia de autodeterminação. Compreendem, em síntese, que a considerar a pessoa em concreto, a autodeterminação seria expressão do princípio da dignidade.

Sob esse matiz, a CDPD, seguida pelo EPD, propôs uma dissociação entre autodeterminação, capacidade mental e capacidade civil $^{22}$, rompendo com o padrão conceitual da dignidade da pessoa humana utilizado nas primeiras declarações de direitos humanos, inclusive a de 1948 (Declaração Universal dos Direitos do Homem, promulgada pela Organização das Nações Unidas). Independentemente da capacidade mental, é importante assegurar a autodeterminação da pessoa como uma forma de respeitar a sua dignidade enquanto sujeito. Nesse sentido é que o artigo 12, parágrafo primeiro da CDPD reafirma que as pessoas com deficiência têm direito ao reconhecimento de sua personalidade jurídica e, consequentemente, à capacidade jurídica.

Segundo G. Peces-Barba (2003, p.28-55), o ideal de dignidade humana foi construído sob um modelo de ser humano ilustrado e delineado por um conjunto de características estéticas e éticas que remetiam a um padrão de perfeição. Pressupunha um protótipo de agente apto a participar do discurso moral por sua capacidade de raciocinar, de sentir e de se comunicar, manifestando as competências indispensáveis ao desempenho de seu papel social (RÓIG, 2008, p.3233). Àqueles considerados incapazes seriam atribuídos direitos não sob o fundamento da sua própria dignidade, mas em virtude de os sujeitos

22 Na explicação do Relatório do Comitê da ONU sobre o artigo 12 da CDPD, é necessário dissociar capacidade jurídica da capacidade mental (que chamamos, nesse texto, de capacidade de agir). Para o ONU, a capacidade jurídica engloba aquilo que entendemos capacidade de direito e capacidade de fato, constituindo importante instrumento para a efetiva inclusão da pessoa na vida social. In verbis: "La capacidad jurídica y la capacidad mental son conceptos distintos. La capacidad jurídica es la capacidad de ser titular de derechos y obligaciones (capacidad legal) y de ejercer esos derechos y obligaciones (legitimación para actuar). Es la clave para acceder a una participación verdadera en la sociedad. La capacidad mental se refiere a la aptitud de una persona para adoptar decisiones, que naturalmente varía de una persona a otra y puede ser diferente para una persona determinada en función de muchos factores, entre ellos factores ambientales y sociales. En virtud del artículo 12 de la Convención, los déficits en la capacidad mental, ya sean supuestos o reales, no deben utilizarse como justificación para negar la capacidad jurídica." (ONU. CRPD/C/11/4, 2016). 
capazes considerá-los merecedores desse favor pelo fato de sua pertença à família humana ${ }^{23}$.

Mesmo assim, apartadas do padrão social e jurídico de normalidade, essas pessoas sofriam e ainda sofrem uma descriminação severa em diversas instâncias da vida legitimada pelo próprio Direito. Qualquer restrição à capacidade mental repercutiria em prejuízo a sua autodeterminação na seara patrimonial e existencial, justificando-lhe a sujeição à curatela, inserta em um modelo firmado primordialmente na substituição de vontade. Grosso modo, perdiam a condição de sujeito para configurarem meros objetos de proteção.

E enquanto meros objetos de proteção, o conjunto de seus direitos de personalidade eram ameaçados ou integralmente sonegados. Não tinham o reconhecimento de sua autonomia sequer para o trato de questões existenciais, tampouco se viam respeitadas em sua privacidade, imagem ou integridade psicofísica. Por meio de uma carta branca para substituir a vontade do curatelado em todos os atos da vida civil, o curador se imiscuía em assuntos existenciais e se via com poder para decidir sobre doação de órgãos ${ }^{24}$ e sobre esterilização em qualquer

23 "Aquellos que no tuvieram esas capacidades podrían tener atribuidos derechos, pero no justificados desde la idea de la dignidad humana, sino como fruto de la decisión de los sujetos capaces al considerar-los como merecedores de dicha atribución." (RÓIG, 2008, p. 35-36).

24 "É ilustrativo dessa questão um julgamento proferido pelo Tribunal de Justiça de São Paulo, no ano de 1986. No âmbito da Apelação Cível 76.123-1, o Tribunal analisou a possibilidade de um interdito com "psicose epilética, na forma demencial", efetuar a doação de um rim a irmão dele, que apresentava insuficiência crônica terminal. A decisão monocrática acolheu o pedido formulado pelo curador do incapaz, de suprimento de consentimento, a partir do qual o transplante seria autorizado. Inconformado, o Ministério Público interpôs recurso de apelação. O Tribunal deu provimento à apelação e reformou a sentença, sob o argumento de que o interdito tinha 'vida simplesmente vegetativa, sem condições de comunicar-se ou manifestar a vontade ainda que de forma defeituosa'. E, em vista da natureza 'personalíssima' da decisão de doar órgãos humanos, o curador não poderia anuir em nome do incapaz. Não aprofundaremos a análise do caso em comento propriamente, se a decisão do Tribunal foi ou não acertada. Interessam-nos os princípios que dele poderemos extrair. Suponhamos, para efeito de argumentação, que o interdito, apesar da doença mental, tivesse condições de manifestar de forma segura, isenta, a sua vontade. Mesmo assim, se reproduzirmos os fundamentos do acórdão (que, para o caso concreto, nos parecem pertinentes), o transplante não poderia ser realizado. A interdição civil, conforme implementada hoje em dia, ao mirar a proteção dos bens do incapaz, acaba suprimindo sua capacidade não apenas para os atos patrimoniais, mas também para as situações existenciais, para o exercício de direitos da personalidade. Com isso, o interdito não pratica os atos existenciais ele próprio, como efeito da perda da capacidade, nem através do curador, dado o caráter personalíssimo desses atos. Ou seja, nesses moldes, a interdição, que seria medida de proteção do incapaz, resulta na verdade em medida de exclusão (SÃO PAULO. TJSP. Ap 76.123-1, 5ª Câmara, j. 14-8-1986, rel. Ruy Camilo)." (LEITE, 2012, p. 302-321). 
parcimônia ${ }^{25}$, a título de exemplo. Semelhantemente às soluções empregadas para assuntos patrimoniais, estendia-se a representação, por substituição de vontade, aos assuntos existenciais, quando a estes somente caberia apresentação ${ }^{26}$.

Ademais, os tradicionais processos de interdição não permitiam a análise pormenorizada das vicissitudes circundantes à história de vida e às preferências de cada pessoa. Observava-se apenas deficiência enquanto uma patologia e não o sujeito de carne, expressão usada por Rodotà $(2014)^{27}$, cujos interesses estavam em discussão. Desconsiderava-se que, independentemente do diagnóstico, o conjunto de fatores pessoais e de experiências externas pode afetar substancialmente o modo como a pessoa passa a responder às suas limitações psíquicas e/ou intelectuais. Fatores como gênero, idade, status socioeconômico, apoio familiar, educação, sexualidade, preferências, etnia e herança cultural podem interferir de tal modo no desenvolvimento de competências e habilidades de cada um que o

25 "SUPRIMENTO JUDICIAL - Curador provisório que pede a esterilização da interditada Acolhimento - Possibilidade - Interpretação histórica e teleológica do decreto $\mathrm{n}^{\circ} 6.949$, que promulga a convenção internacional sobre direitos das pessoas com deficiência e seu protocolo facultativo - Decisão reformada - Recurso provido". (SÃO PAULO. TJ-SP. APL: 00009916620148260654 SP 0000991-66.2014.8.26.0654, Relator: Alvaro Passos, Data de Julgamento: 22/09/2015, $2^{\text {a }}$ Câmara de Direito Privado, Data de Publicação: 29/09/2015); em outra decisão, "Alvará Judicial. Cirurgia de Laqueadura. Pessoa interditada portadora de deficiência mental e motora e que já é mãe. Indicação feita pelo médico. Interesse processual e possibilidade jurídica do pedido demonstradas. Extinção afastada. Aplicação do art. 515, $\S 3^{\circ}$, do CPC. Tendo em vista que a autora já passou pelo processo de inter'dição, por outro lado, despicienda a necessidade de realização de nova perícia médica pelo IMESC. Procedência do pedido. Sentença reformada. Recursos providos." (SÃO PAULO. TJ-SP. APL: 00007742320148260654 SP 0000774-23.2014.8.26.0654, Relator: Pedro de Alcântara da Silva Leme Filho, Data de Julgamento: 12/08/2015, $8^{\text {a }}$ Câmara de Direito Privado, Data de Publicação: 13/08/2015).

26 "De ordinário, nos atos da vida, cada um pratica, por si, os atos que hão de influir, ativa ou passivamente na sua esfera jurídica. Os efeitos resultam de atos em que o agente é presente; pois os pratica, por ato positivo ou negativo. A regra é a presenteção, em que ninguém faz o papel de outrem, isto é, em que ninguém representa. (MIRANDA, 2012, p.307).

27 "Se produce, pues, la transición del individuo a la persona, del sujeto de derecho al sujeto de carne que permite dar pregresiva relevancia al destino de socialización de la persona y al destino de naturaliza de su organismo." (RODOTÀ, 2014, p.143-144). 
diagnóstico, por si, não constitui um dado suficiente para aferir o grau de discernimento ou o tipo de apoio de que a pessoa necessita ${ }^{28}$.

Linhas gerais, é isso que a CDPD e o EPD tentaram reverter. Reconhecendo a todas as pessoas igual dignidade, também compreendem a necessidade de se reconhecer a todas a igual capacidade jurídica, indispensável ao exercício da autonomia. Capacidade jurídica, reafirma-se, aquela que envolve capacidade de fato e capacidade de gozo. Como o intento é garantir a dignidade dessas pessoas e lhes oferecer o suporte necessário, não estarão desamparadas se para o exercício da capacidade precisarem de algum apoio. Não se pode mais admitir que a capacidade civil se posicione como uma barreira institucional tendente a ampliar o quadro de desigualdade e a obstar o gozo dos direitos humanos, fundamentais e de personalidade. Luigi Ferrajoli (2009) ${ }^{29}$ há muito tempo já alertava sobre a aplicação do status da capacidade e da cidadania como barreiras ao acesso aos direitos fundamentais, especialmente à igualdade.

28 "De acordo com a World Health Survey, aproximadamente 785 milhões de pessoas (15,6\%) com 15 anos ou mais vivem com alguma forma de de!ciência, enquanto a Global Burden of Disease estima algo em torno de 975 milhões de pessoas $(19,4 \%)$. Dessas, a World Health Survey estima que 110 milhões de pessoas $(2,2 \%)$ possuem dificuldades funcionais muito significativas, enquanto a Global Burden of Disease estima que 190 milhões $(3,8)$ possuem uma "deficiência grave" - o equivalente às deficiências inferidas por condições tais como a tetraplegia, a depressão grave ou a cegueira. Somente a Global Burden of Disease mensura a infância com deficiência (0-14 anos), a qual está estimada em 95 milhões de crianças (5,1\%), das quais 13 milhões $(0,7 \%)$ possuem "deficiências graves". Organização Mundial da Saúde. Relatório mundial sobre a deficiência produzido em 2011.

29 Ferrajoli (2009, p.22) denuncia que a cidadania e a capacidade civil tem sido os status que ainda limitam a igualdade das pessoas humanas. Segundo ele, "estas clases de sujetos han sido identificadas por los status determinados por la identidad de 'persona' y/o de 'ciudadano' y/o 'capaz de obrar' que, como sabemos, en la historia han sido objeto de las más variadas limitaciones y discriminaciones. Personalidad, ciudadanía y capacidad de obrar, en cuanto condiciones de la igual titularidad de todos los (diversos tipos) de derechos fundamentals, son consecuentemente los parámetros tanto de la igualdad como de la desigualdad en droits fondamentaux. Prueba de ello es el hecho de que sus presupuestos pueden - y han sido históricamente - más o menos extensos: restringidísimos en el pasado, cuando por sexo, nacimiento, censo, instrucción o nacionalidad se excluía de ellos a la mayor parte de las personas físicas, se han ido ampliado progresivamente aunque sin llegar a alcanzar todavía, ni siquiera en la actualidad, al menos por lo que se refiere a la ciudadanía y a la capacidad de obrar, una extension universal que comprenda a todos los seres humanos". 
Em face de todo o substrato teórico até aqui condensado, importa analisar as mudanças produzidas pelo EPD no plano das capacidades e o conteúdo que ela atribui à dignidade.

O EPD estabeleceu que a deficiência não é critério para aferição da capacidade (art.6 ${ }^{\circ}$, caput), fazendo ecoar o entendimento da própria CDPD que reconhece a capacidade legal a todos. Nesse particular, embora a CDPD use o termo "capacidade legal"30 está mesmo se referindo à capacidade jurídica (voltamos a repetir), consoante esclarece o relatório intitulado "Observación general sobre el artículo 12: igual reconocimiento como persona ante la ley", elaborado pelo Comitê sobre os direitos da pessoas com deficiência da Organização das Nações Unidas. ${ }^{31}$ Com isso revogou os dispositivos do CC/2002 que faziam referencia à deficiência como causa de incapacidade civil relativa ou absoluta. Para evitar mal entendido, expressamente alterou a redação dos artigos $3^{\circ}$ e $4^{\circ}$, por meio do seu art. $114^{32}$.

30 O Código Civil Alemão também se refere à capacidade legal e não à capacidade juridical.

31 ONU. CRPD/C/11/4. "Item 8. El artículo 12 de la Convención afirma que todas las personas con discapacidad tienen plena capacidad jurídica. La capacidad jurídica les ha sido negada de forma discriminatoria a muchos grupos a lo largo de la historia, como las mujeres (sobre todo al contraer matrimonio) y las minorías étnicas. Sin embargo, las personas con discapacidad siguen siendo el grupo al que más comúnmente se le niega la capacidad jurídica en los ordenamientos jurídicos de todo el mundo. El derecho al igual reconocimiento como persona ante la ley entraña que la capacidad jurídica es un atributo universal inherente a todas las personas en razón de su condición humana y debe defenderse para las personas con discapacidad en igualdad de condiciones con las demás. La capacidad jurídica es indispensable para el ejercicio de los derechos económicos, sociales y culturales. Adquiere una importancia especial para las personas con discapacidad cuando tienen que tomar decisiones fundamentales en lo que respecta a la salud, la educación y el trabajo. (En muchos casos, la negación de capacidad jurídica a las personas con discapacidad ha conducido a privarlas de muchos derechos fundamentales, como el derecho de voto, el derecho a casarse y fundar una familia, los derechos de reproducción, la patria potestad, el derecho a otorgar su consentimiento para las relaciones íntimas y el tratamiento médico y el derecho a la libertad.)".

32 "Art. 114. A Lei no 10.406, de 10 de janeiro de 2002 (Código Civil), passa a vigorar com as seguintes alterações: 'Art. $3^{\circ}$ São absolutamente incapazes de exercer pessoalmente os atos da vida civil os menores de 16 (dezesseis) anos. I - (Revogado); II - (Revogado); III - (Revogado).' (NR)

'Art. 4 São incapazes, relativamente a certos atos ou à maneira de os exercer: [...]. II - os ébrios habituais e os viciados em tóxico; III - aqueles que, por causa transitória ou permanente, não puderem exprimir sua vontade; [...] Parágrafo único. A capacidade dos indígenas será regulada por legislação especial.' (NR) 
De um modo mais especifico, o Comitê da ONU dispôs que devem ser abolidas todas as práticas cujos efeitos vierem a violar o artigo 12 , a fim de que as pessoas com deficiência possam recobrar a sua plena capacidade jurídica.

El Comité reafirma que el hecho de que una persona tenga una discapacidad o una deficiencia (incluidas las deficiencias físicas o sensoriales) no debe ser nunca motivo para negarle la capacidad jurídica ni ninguno de los derechos establecidos en el artículo 12 Todas las prácticas cuyo propósito o efecto sea violar el artículo 12 deben ser abolidas, a fin de que las personas con discapacidad recobren la plena capacidad jurídica en igualdad de condiciones con las demás.

Entenda-se capacidade jurídica, conforme esclarecimento do Comitê, a capacidade de gozo e a capacidade de exercício, de sorte que à pessoa com deficiência seja reconhecida como ator jurídico apto a realização de atos com efeitos jurídicos - mesmo os de cunho patrimonial. Para dirimir qualquer dúvida, veja-se o art. 12, parágrafo 5 que permite à pessoa com deficiência ser proprietária, herdeira de bens, controladora dos próprios assuntos econômicos, com acesso igualitário a empréstimos bancários, hipotecas e outras modalidades de crédito financeiros, salvaguardando-as para que não sejam privadas de seus bens de maneira arbitrária.

Há uma dissociação entre os conceitos de capacidade jurídica e de capacidade mental. A primeira constitui a possibilidade de figurar nas relações jurídicas como titular de direitos e deveres (capacidade de direito ou de gozo) somada à capacidade para exercer esses direitos e deveres por si com legitimação para atuar (capacidade de fato ou de exercício). Essa capacidade jurídica integral é que se afigura como chave para a efetiva participação na arena política, civil e social. Já a capacidade mental (que remete à capacidade de agir) diz respeito à aptidão que tem o sujeito para a tomada de decisões, sendo variável de pessoa para pessoa a depender de uma gama de fatores pessoais, ambientais e sociais. Porém, em razão do que dispõe o art.12 da CDPD, eventuais déficits na capacidade mental, supostos ou reais, não podem ser utilizados como justificativa para restringir ou negar a capacidade 
jurídica da pessoa. Nessas hipóteses, deve Ihe ser franqueado o apoio que precisar.

13. En la mayoría de los informes de los Estados partes que ha examinado hasta la fecha el Comité se mezclan los conceptos de capacidad mental y capacidad jurídica, de modo que cuando se considera que una persona tiene una aptitud deficiente para adoptar decisiones, a menudo como consecuencia de una discapacidad cognitiva o psicosocial, se le retira en consecuencia su capacidad jurídica para adoptar una decisión concreta. Esto se decide simplemente en función del diagnóstico de una discapacidad (criterio basado en la condición), o cuando la persona adopta una decisión que se considera que tiene consecuencias negativas (criterio basado en los resultados), o cuando se considera que la aptitud de la persona para adoptar decisiones es deficiente (criterio funcional). En todos esos criterios, la discapacidad de la persona o su aptitud para adoptar decisiones se consideran motivos legítimos para negarle la capacidad jurídica y rebajar su condición como persona ante la ley. El artículo 12 no permite negar la capacidad jurídica de ese modo discriminatorio, sino que exige que se proporcione apoyo en su ejercicio.

Pela lógica da CDPD e do EPD defere-se igual capacidade a todos. Na hipótese de a pessoa necessitar de apoio ao exercício de sua capacidade, a Sociedade e o Estado devem Ihe disponibilizar uma rede de apoio que envolve desde o mero auxílio informal (art.7०.., CDPD) até aqueles tipos específicos como a Tomada de Decisão Apoiada e a curatela, esta última constituindo um mecanismo de apoio mais intenso.

A solução proposta pelo EPD não tem agradado à comunidade dos juristas e já tramita no Senado, Projeto de Lei n 757/2015, tendente à sua reformulação, praticamente recobrando a situação anterior, sob a justificativa de que as mudanças envidadas pelo Estatuto mais desprotegem que amparam. (SIMÃO, 2016). O objetivo desse projeto é alterar o Código Civil, o EPD e o CPC/2015 para desvincular automaticamente a condição de pessoa com deficiência de qualquer presunção de incapacidade, mas garantindo que qualquer pessoa, com ou sem deficiência, tenha o apoio de que necessite para os atos 
da vida civil. No entanto, referido projeto acaba repristinando dois incisos da antiga redação do art. $3^{\circ}$ do Código Civil que estabelece como absolutamente incapazes: "II - os que não tenham qualquer discernimento para a prática desses atos, conforme decisão judicial que leve em conta a avaliação biopsicossocial. III - os que, mesmo por causa transitória, não puderem exprimir sua vontade". Nesse aspecto é que se torna temerário.

Qualquer mudança que se pretenda realizar no EPD deve ser muito bem alinhada à luz da Convenção. Não obstante o susto da comunidade jurídica ao retirar-se as pessoas com déficit em seu discernimento do rol dos absolutamente incapazes, essa mudança não está dissociada do eixo axiológico da CDPD, que envida uma reinterpretação dos institutos jurídicos. Por isso, insiste-se que o EPD associado à CDPD não deixa a pessoa desamparada ou desassistida. Pelo contrário, desde a CDPD confia-se ao Estado signatário o dever de instituir um sistema de apoio e salvaguardas voltados para viabilizar o exercício daquela capacidade jurídica concedida às pessoas com deficiência cuja limitação seja mais severa (art. 12). Mantendo-se, no Brasil, a curatela, tem-se que a mudança substancial foi no sentido de mudar o foco do direito protetivo do sistema de substituição para o sistema de apoio (MENEZES, 2015), de modo que esse seja estritamente modulado às necessidades da pessoa com algum abalo na sua higidez psíquica. Um dos maiores avanços do EPD é, indubitavelmente, que a sentença judicial que estabelece a curatela seja dada para as necessidades específicas da pessoa, e não que essa tenha que se adaptar a categorias legais pré-estabelecidas (TEIXEIRA, 2009; RODRIGUES, 2009).

Apoio significa ajuda, proteção, auxílio. Na língua inglesa, seria o support; no italiano, o sostegno; no espanhol, apoyo. Visa promover e proteger a autonomia da pessoa para que possa, de um modo independente, realizar as suas próprias escolhas e desenvolver seu projeto de vida (art. $3^{\circ}$ - CDPD $)^{33}$. Esse modelo ou sistema de

33 "Art. $3^{\circ}$. Os princípios da presente Convenção são: a) O respeito pela dignidade inerente, a autonomia individual, inclusive a liberdade de fazer as próprias escolhas, e a independência das pessoas;" 
apoio diverge da representação tradicional porque respeita a vontade decisória do apoiado na maior medida possível, favorecendo a que ele mesmo, sempre que possível, venha a decidir e se projetar com uma vida independente.

A depender das limitações da pessoa, se determinará o apoio que, de acordo com o preâmbulo da CDPD, alínea $\mathrm{J}^{34}$ pode ser mais intenso, induzindo, inclusive, a possibilidade de uma curatela com uma gama maior de poderes e deveres. Em todo caso, o apoio no exercício da capacidade jurídica deve respeitar os direitos, a vontade e as preferências das pessoas com deficiência e nunca deve consistir em uma decisão fria tomada em substituição a elas. E até aqui, haverá limites para a curatela, conforme fixados em lei. Ao lado dos mecanismos de apoio, o Estado deve criar as salvaguardas apropriadas para que sejam garantidos os direitos, a vontade e as preferências da pessoa, de modo que sejam protegidas de toda e qualquer forma de abuso.

Em síntese, a restrição à capacidade jurídica somente poderá ser realizada se o critério for aplicável a todos, indistintamente, e não apenas em relação às pessoas com deficiência. Nesse aspecto, se o sujeito está em coma, por exemplo, o estado de saúde que impede a comunicação da vontade poderia ser um critério de restrição de capacidade porque aplicável a qualquer pessoa, independentemente de um diagnóstico de deficiência. In verbis, o trecho do relatório elaborado pelo COMITÉ da ONU,

Sin embargo, el derecho al igual reconocimiento como persona ante la ley y a no sufrir discriminación exige que cuando el Estado niegue la capacidad jurídica, debe hacerlo por los mismos motivos a todas las personas. La negación de la capacidad jurídica no debe basarse en un rasgo personal como el género, la raza o la discapacidad, ni tener el propósito o el efecto de tratar a esas personas de manera diferente.

34 Preâmbulo da CDPD "Os Estados Partes da presente Convenção, [...].

J. Reconhecendo a necessidade de promover e proteger os direitos humanos de todas as pessoas com deficiência, inclusive daquelas que requerem maior apoio, [...]." 
Portanto, o status personae é a medida máxima que assegura ao sujeito a condição de pessoa e, consequentemente, a possibilidade de integrar as relações jurídicas mais diversas, constituindo direitos e/ ou obrigações (DANTAS, 1979, p.169). A nacionalidade, a posição da pessoa na família ou mesmo a capacidade civil não podem justificar a restrição ao exercício e ao gozo dos direitos existenciais, quando muito, representam fórmulas descritivas de situações jurídicas específicas. ${ }^{35} \mathrm{~A}$ cidadania é condicionante para o exercício de muitos direitos políticos, como a elegibilidade e o direito de votar; a posição do sujeito na família informa a sua condição de pater ou de filius; a capacidade civil, por sua vez, pode ser determinante para a prática de atos jurídicos potestativos, a exemplo da compra e venda de bens imóveis, do casamento, do testamento etc. Nenhuma dessas posições, porém, poderá implicar na supressão ou restrição de direitos existenciais atrelados imediatamente à realização de sua personalidade.

Se voltarmos o olhar para a Alemanha, revogaram-se a interdição com os institutos da Curatela e da Tutela, instituindo Betreuung (§§ 1896 ff. BGB) como uma espécie de cuidado jurídico. No geral, mantém-se a capacidade jurídica em virtude do direito fundamental à autodeterminação previsto na Constituição (Art. 2 n. ${ }^{\circ} 1 \mathrm{GG}$ ). (MONTIJANO, 2016).

O novo Código Civil e Comercial argentino chegou a utilizar a expressão apoio - "Sistema de apoio ao exercício da capacidade" como título do parágrafo que trata matéria na sessão sobre as restrições à capacidade civili $^{36}$. A Argentina dispôs que são incapazes aquelas

35 Na elaboracão de Francesco Prosperi (2013, p. 14) "Le considerazioni svolte consentono, dunque, di concludere che la nozione di status, fuori del significato tradizionale di commisurazione della stessa capacità giuridica dei soggetti in relazione alla loro appartenenza ad una determinata categoria sociale, inaccettabile nei moderni ordinamenti ispirati al principio dell'eguaglianza dei cittadini, assume un valore puramente convenzionale, di formula sinteticamente descrittiva di una serie di effetti o situazione piuttosto che altre."

36 Código Civil e Comercial Argentino - "Parágrafo $2^{\circ}$ Sistemas de apoyo al ejercicio de la capacidad. ARTICULO 43.- Concepto. Función. Designación. Se entiende por apoyo cualquier medida de carácter judicial o extrajudicial que facilite a la persona que lo necesite la toma de decisiones para dirigir su persona, administrar sus bienes y celebrar actos jurídicos en general. Las medidas de apoyo tienen como función la de promover la autonomía y facilitar la comunicación, la comprensión y la manifestación de voluntad de la persona para el ejercicio de sus derechos. El interesado puede proponer al juez la designación de una o más personas de su confianza para que le presten apoyo. El juez debe evaluar los alcances de la designación y procurar la protección de la persona respecto de eventuales conflictos de intereses o influencia indebida. La resolución debe establecer la condición y la calidad de las medidas de apoyo y, de ser necesario, ser inscripta en el Registro de Estado Civil y Capacidad de las Personas." 
pessoas que assim forem declaradas por sentença judicial e na extensão desta (art. 24, c). Sustenta que toda restrição à capacidade deve ser estabelecida em benefício da própria pessoa (art.31, c), priorizandose sempre as alternativas terapêuticas menos restritivas dos direitos e liberdades (art.31, f). Na sentença que limita a capacidade, o juiz deve designar os apoios necessários previstos no art. 43, especificando as funções com os ajustes razoáveis em função das necessidades e circunstanciais pessoais do apoiado. Todo apoio designado deve promover a autonomia e favorecer a que as decisões sempre estejam atreladas às preferências da pessoa protegida. Excepcionalmente, quando a pessoa se encontrar absolutamente impossibilitada da interação com seu entorno e de expressar a sua vontade por qualquer modo, meio ou formato, sendo ineficaz o sistema de apoio, o juiz poderá designar um curador com poderes de representação.

Portanto, observa-se a modificação substancial no plano do direito protetivo, com as alterações havidas no regime das incapacidades. Visando a promover a autonomia, elemento que dá mobilidade à pessoa na construção de sua própria biografia e na direção do seu destino, migrou-se do modelo de substituição de vontade para o modelo de apoio. A pessoa que necessita de apoio, nem por isso perderá a capacidade. Na hipótese de fixação da curatela, quando o apoio precisar ser mais intenso, ainda haverá esfera da personalidade alheias aos poderes do curador. Além disso, mesmo quanto às questões legadas à decisão do curador, este já não agirá pelo caminho frio da substituição de vontade, pois o EPD lhe incumbe de perquirir a vontade, os interesses fundamentais e as preferências do curatelado que deverão nortear sua decisão.

\section{Conclusão}

Em suma, observa-se um giro estrutural no regime das incapacidades para garantir a inclusão da pessoa com deficiência e por admitir que a lida com os assuntos existenciais não pode ser conduzida 
pelos mesmos parâmetros talhados para definir a capacidade para a prática de negócios patrimoniais. Assim, tanto se reconhece a capacidade jurídica plena à pessoa com deficiência, desconstruindo essa condição como critério discriminatório e ainda se admite incindibilidade entre capacidade de gozo e capacidade de exercício quanto aos interesses existenciais presentes no plano dos direitos da personalidade.

Não obstante, a capacidade jurídica (capacidade de fato e de gozo) reconhecida às pessoas com deficiência não se subsume apenas ao plano dos direitos existenciais, mas também se expande para a seara patrimonial, a considerar o art. 12, item 5. Em qualquer caso, porém, a depender da necessidade específica da pessoa em concreto, é que se dispensará a ela um apoio ao exercício de sua capacidade. É no momento decisório do processo judicial que deverá ser pensado e avaliado como se dará o exercício dos seus direitos da personalidade, para que a pessoa com deficiência possa participar das decisões na maior medida possível, seja nos momentos de concretude de sua liberdade existencial, seja através da reconstrução biográfica da sua vontade. Queiramos ou não, a CDPD determinou a inclusão efetiva dessas pessoas. Nem por isso negligenciou eventuais demandas protetivas. Por isso mesmo é que previu a necessidade de instituírem apoios e salvaguardas para favorecer o exercício da capacidade jurídica e para por a salvo os seus direitos de abusos e lesões. Migramos de um modelo protetivo de substituição de vontade para um modelo pautado no apoio que busca favorecer a emancipação do sujeito sem Ihe negar a proteção de que necessitar. É a partir desse novo paradigma, dessa nova ratio que os institutos de direito civil deverão, então, ser reinterpretados.

Em face de tudo o que foi dito, não podemos cogitar repetir que a pessoa com deficiência sob curatela seja incapaz. Até mesmo para evitar os estigmas que o regime das incapacidades produziu ao longo da história, optamos por utilizar a expressão pessoa com capacidade restringida. 


\section{Referências}

AMARAL NETO, Francisco dos Santos. A autonomia privada como princípio fundamental da ordem jurídica. Perspectiva estrutural e funcional. Revista de Direito Civil, Imobiliário, Agrário e Empresarial, São Paulo, ano 12, v. 46, p. 9, out./dez. 1988.

AMARAL, Francisco. Direito civil: introdução. 6. ed. Rio de Janeiro: Renovar, 2006.

ANDRADE, Manuel Domingues de. Teoria geral da relação jurídica. Coimbra: Almedina, 1997.

ARENA, Giacomo. Enciclopedia del Diritto. Milano: Giuffrè, 1958. v. $X X$.

MORAES, Maria Celina Bodin de. Perspectivas a partir do direito civil-constitucional. In: TEPEDINO, Gustavo (Org.). Direito civil contemporâneo: Novos problemas à luz da legalidade constitucional. São Paulo: Atlas, 2008. p. 997-1010.

CHAMOUN, Ebert. Instituições de direito romano. 6. ed. Rio de Janeiro: Editora Rio, 1977.

CARBONERA, Silvana. Reflexões acerca do consentimento informado de incapazes em intervenções médico-cirúrgicas e pesquisas biomédicas. Ciência e opinião, Curitiba, v. 1, n. 2/4, jul. 2003/dez. 2004.

DANTAS, San Tiago. Programa de direito civil. Rio de Janeiro: Editora Rio, 1979.

EBERLE, Simone. Mais capacidade, menos autonomia: o estatuto da menoridade no novo Código Civil. Revista Brasileira de Direito de Família, Porto Alegre, v. 24, n. 24, jun./jul. 2004.

EBERLE, Simone. A capacidade entre o fato e o direito. Porto Alegre: Sérgio Antonio Fabris, 2006.

FERRAJOLI, Luigi. Los fundamentos de los derechos fundamentales. Madrid: Trotta, 2009. 
KONDER, Carlos Nelson de Paula; TEIXEIRA, Ana Carolina Brochado. Crianças e adolescentes na condição de pacientes médicos: desafios da ponderação entre autonomia e vulnerabilidade. Pensar: Revista de Ciências Jurídicas, Fortaleza, v. 21, n. 1, p. 73, jan./abr. 2016.

LISELLA, Gaspare. Interdizione per infermità mentale e situazioni giuridiche esistenziali. Rassegna di Diritto Civile. Nápoli: Edizione Scientifiche Italiane,1982.

LÔBO, Paulo. Direito Civil: parte geral. São Paulo: Saraiva, 2010.

MARTINS-COSTA, Judith. Capacidade para consentir e esterilização de mulheres tornadas incapazes pelo uso de drogas: notas para uma aproximação entre a técnica jurídica e a reflexão bioética. In: MARTINS-COSTA, Judith; MÖLLER, Letícia Ludwig (Org.). Bioética e responsabilidade. Rio de Janeiro: Forense, 2009. p. 299-346.

MEIRELES, Rose Melo Vencelau. Autonomia privada e dignidade humana. Rio de Janeiro: Renovar, 2009.

MEIRELLES, Jussara. O ser e o ter na codificação civil brasileira: do sujeito virtual à clausura patrimonial. In: FACHIN, Luiz Edson (Coord.). Repensando fundamentos do Direito civil brasileiro contemporâneo. Rio de Janeiro: Renovar, 2000. p. 87-114.

MENEZES, Joyceane Bezerra. A capacidade dos incapazes: o diálogo entre a Convenção da ONU sobre os direitos da pessoa com deficiência e o Código Civil Brasileiro. In: RUZYK, Carlos Eduardo P. et al. Direito Civil Constitucional: a ressignificação da função dos institutos fundamentais do Direito Civil Contemporâneo e suas consequências. Florianópolis: Conceito, 2014, p. 51-74.

\section{O direito protetivo no Brasil após a convenção sobre a}

proteção da pessoa com deficiência: impactos do novo CPC e do Estatuto da Pessoa com Deficiência. Disponível em: <http://civilistica. com/wp-content/uploads/2016/01/Menezes-civilistica.com-a.4.n.1.2015. pdf>. Acesso em: 20 maio 2016. 
MIRANDA, Pontes de. Tratado de Direito Privado: parte Especial. Atualizado por Marcos Bernardes Mello, Marcos Ehrhardt Jr. 1. ed. São Paulo: RT, 2012.

MONTIJANO, Martín García-Ripoll. La nueva legislación alemana sobre la tutela o asistencia (Betreuung) de los enfermos físicos y psíquicos: otro modelo. Disponível em: <http://laleydigital.laley.es/ Content/Inicio.aspx>. Acesso em: 10 fev. 2016.

PALACIOS, Agustina; ROMAÑACH, Ravier. El modelo de la diversidad: la bioetica y los derechos humanos como herramientas para alcanzar la plena dignidade en la diversidad funcional. España: Ediciones Diversitas. 2006. Disponível em: <http://e-archivo.uc3m.es/ bitstream/handle/10016/9899/diversidad.pdf?sequence=1>. Acesso em: 03 mar. 2016.

PECES-BARBA, Gregório. La dignidad de la persona desde la Filosofia del Derecho. Dykinson: Madrid, 2003. (Col. Cuadernos Bartolomé de las casas, n. 26).

PERLINGIERI, Pietro. La personalità umana nell'ordinamento giuridico. Camerino-Napoli: Edizioni Scientifiche Italiane, 1972.

Italiane, 2002.

Manuale di Diritto Civile. 3. ed. Napoli: Edizioni Scientifiche . Perfis do Direito civil. Trad. Maria Cristina De Cicco. 2. ed. Rio de Janeiro: Renovar, 2002.

RODRIGUES, Rafael Garcia. A pessoa e o ser humano no novo Código Civil. In: TEPEDINO, Gustavo (Coord.). A parte geral do Código Civil: estudos na perspectiva civil-constitucional. Rio de Janeiro: Renovar, 2003. p. 1-35.

RODOTÀ, Stefano. La vita e le regole: tra diritto e non diritto. Milano: Feltrinelli, 2006.

. El derecho a tener derecho. Madrid: Editorial Trota, 2014.

RODRIGUES, Renata de Lima. Incapacidade, curatela e autonomia privada: estudos no marco do Estado democrático de Direito. 2007. 
201 f. Dissertação (Mestrado em Direito) - Pontifícia Universidade Católica de Minas Gerais. Programa de Pós-Graduação em Direito, Belo Horizonte, 2007.

ROIG, Rafael de Asis. Derechos humanos y discapacidad. Algunas reflexiones derivadas del analise de la discapacidad desde la teoria de los derechos. In: CAMBOY CERVEJA, Ignácio. Igualdad, no discriminacion y discapacidad: una vision integradora de las realidades española y argentina. España: Dikinson, 2008. p. 17-50.

SÁ, Maria de Fátima Freire; MOUREIRA, Diogo Luna. A capacidade dos incapazes: saúde mental e uma releitura da teoria das incapacidades no direito privado. 1. ed. Rio de Janeiro: Lumen Juris, 2011.

SILVA PEREIRA, Caio Mário da. Instituições de Direito Civil. 18. ed. Rio de Janeiro: Forense, 1997. v. I.

. Instituições de Direito privado. 20. ed. atualiz. Maria Celina Bodin de Moraes. Rio de Janeiro: Forense, 2004. v. I.

STANZIONE, Pasquale. Enciclopedia giuridica. Capacità. Roma: Istituto della Enciclopedia Italiana, 1988. v. V.

STANZIONE, Pasquale. Persona física. Diritto Civile. In: AUTORINO, Gabriella; STANZIONE, Pasquale (Org.). Diritto civile e situazione esistenziali. Torino: G. Giappichelli Editore, 1997. p. 104-119.

TEIXEIRA, Ana Carolina Brochado; SALES, Ana Amélia Ribeiro; SOUZA, Maria Aparecida Freitas de. Autonomia privada da criança e do adolescente: uma reflexão sobre o regime das incapacidade. Revista de Direito de Famílias e Sucessões, Rio de Janeiro, n.0, p. 61-65, out./nov. 2007.

TEIXEIRA, Ana Carolina Brochado. Deficiência psíquica e curatela: reflexões sob o viés da autonomia privada. Revista Brasileira de Direito das Famílias e Sucessões, Porto Alegre, v. 7, p. 64-79, 2009. 
TEPEDINO, Gustavo. A tutela da personalidade no ordenamento civilconstitucional brasileiro. In: . Temas de Direito civil. 3. ed. Rio de Janeiro: Renovar, 2004. p. 26.

. O Direito civil constitucional e suas perspectivas atuais. In: TEPEDINO, Gustavo (Org.). Direito civil contemporâneo: novos problemas à luz da legalidade constitucional. São Paulo: Atlas, 2008. p. 356-371.

TUHR, A. von. Derecho civil. Volumen I. Las personas. Marcial Pons, Ediciones Jurídicas y Sociales, S.A.: Madrid, 1999.

Autoras convidadas 